\title{
Computer information technology modeling tribological systems
}

\author{
Ruslan Sorokatyi ${ }^{1 *}$, Aleksandr Dykha ${ }^{1}$, Oleksandr Pasichnyk ${ }^{1}$, Tetiana Skrypnyk ${ }^{1}$ \\ ${ }^{I}$ Khmelmitskyi National University, Ukraine \\ *E-mail: rsorokaty@gmail.com
}

\section{Abstract}

It has been proposed to use the triboelement method to improve the elements of information technology $\mathrm{CAD} / \mathrm{CAM} / \mathrm{CAE}$ - tribological systems. The method uses a unified mathematical apparatus and a methodological approach in modeling wear of various types of friction units and takes into account the requirements for the mathematical support of CAD/CAM / CAE systems. The mathematical support of information technology and the generalized algorithm for the interaction of the wear calculation module with the elements of $\mathrm{CAD} / \mathrm{CAM} / \mathrm{CAE}$ - systems have undergone sufficient testing through the implementation of software and verification of the calculation results.

Keywords: information technology, software, CAD/CAM/ CAE, triboelement method, design automation

\section{Introduction}

Design automation is a complex discipline, the components of which are a lot of modern information technologies. This determines its special place in the range of CAD / CAM / CAE information technologies complexes as the main automation tool for the design of complex modern software systems. Currently, CAD / $\mathrm{CAM}$ / CAE - complexes have become an effective tool in engineering. They allow computer simulation methods to evaluate the performance of a technical system in a given period of time. The adequacy of the models used in CAD / CAM / CAE complexes depends on taking into account the physical processes that determine the behavior of technical systems. In this regard, it is necessary to improve the elements of information technology. In particular, the mathematical and algorithmic support of $\mathrm{CAD} / \mathrm{CAM} / \mathrm{CAE}$ are the systems that take into account the influence of physical processes in mathematical models.

One of the most important and influencing behavior of technical systems is the wear processes of elements. Therefore, the main direction of improving the CAD / CAM/ CAE software systems at the present stage is the development of calculation methods for the analysis of wear processes.

\section{Background and problem definition}

Recently, in the calculation modules of CAD / CAM / CAE - systems, attempts have been made to take into account the influence of wear on the behavior of technical systems by simulating and analyzing the physical processes occurring in the wear process.

In [1-5], the authors solve the problem by dividing the complex problem of assessing the wear of friction units into a number of problems. These problems can be solved by means of CAD / CAM / CAE-complexes with the subsequent use of calculation results to assess the wear of friction pairs.

In some $\mathrm{CAD} / \mathrm{CAM} / \mathrm{CAE}$ - systems for modeling wear processes, the following algorithm is implemented $[1,2]$ :

- in the $\mathrm{CAD} / \mathrm{CAM} / \mathrm{CAE}$ solver - $\mathrm{ABAQUS}$ systems, the contact geometric parameters were determined;

- the results of the calculation analysis were transferred to an external software application, where the depreciation was calculated;

- the results of the calculation of wear were transferred to the preprocessor to build a new finite element model and carry out VAT calculations taking into account changes in geometry due to wear; 

reached.

- the above procedures were repeated until the set value of the wear of the friction pair elements was

The main disadvantage of this algorithm is the constant restructuring of the entire finite element grid, which leads to a significant increase in the calculation time. Another approach for taking into account physical processes that occur during wear in models was implemented by MSC Software, namely the use of integrated modules in a CAD / CAM / CAE system. Marc / Mentat CAD / CAM / CAE system developers have included a module for calculating wear using several deterministic wear models [10-12]. A similar architectural solution was implemented by the developers of the CAD / CAM/CAE-system ANSYS. A wear calculation module was included in the system based on the use of the Archard model for steady abrasive wear [6-9].

This approach has the following features. If the geometry of the friction pair changes, after a wear cycle, there is no need to rebuild the entire finite element grid. It is enough to change the coordinates of only the nodes of the elements that were in the contact zone and have wear. This will significantly reduce the time of calculation analysis.

The models used to describe the wear processes in $\mathrm{CAD} / \mathrm{CAM} / \mathrm{CAE}$ - systems should be invariant to the methods of obtaining the initial data for determining the parameters of the models. It is impossible to be based only on theoretical models, since in tribology a significant part of the data was obtained experimentally.

The fact that the wear process is a random process is also ignored. In addition to the main prevailing factors, a large number of random factors affect wear. The combined effect of these factors at the physical level has not been fully studied either theoretically or experimentally. The influence of factors that are not taken into account in wear models leads to the fact that the wear process behaves as a random process. For an adequate description of the wear process, the finction of the mathematical expectation of wear over time and the dispersion of values relative to this function at each moment of time should be determined.

The analysis allows us to formulate the requirements for the mathematical support of information technology for $\mathrm{CAD} / \mathrm{CAM} / \mathrm{CAE}$ systems of the tribological sector. Namely.

- The software should be based on the principles of spatio-temporal discretization, and be able to interact with other calculation modules of the CAD / CAM / CAE system.

- Mathematical models should be based on the use of a unified mathematical apparatus and methodological approach to describe the behavior of various types of technical tribosystems.

- Models should describe the wear process as a non-stationary random process.

The aim of this work is to improve the mathematical and algorithmic support of information technology of $\mathrm{CAD} / \mathrm{CAM} / \mathrm{CAE}$-systems of tribological direction, taking into account these requirements.

\section{Improving the mathematical support of information technology CAD / CAM / CAE-systems of tribological direction}

It has been proposed to use a numerical method for modeling the behavior of tribosystems, the method of triboelements (MTE), as the basic method for the mathematical support of information technology for CAD / CAM / CAE systems of the tribological sector [13]. This method most fully takes into account the basic requirements for the software of $\mathrm{CAD} / \mathrm{CAM}$ / CAE-systems. It can be implemented in their architecture as a separate calculation module or integrated directly into one of the existing modules.

The triboelement method is based on an iterative approach, which involves considering a number of discrete states through which the tribosystem passes in the process of functioning. This method (like most modeling methods in SAE modules) is based on spatio-temporal discretization. This allows you to organize the interaction of the calculation modules at the level of the source data and the calculation results. To describe the behavior of tribosystems, the method uses a unified mathematical apparatus and a methodological approach to simulate the wear of various types of friction units. The method takes into account a wide range of factors affecting the course of wear processes and their changes in the process of functioning.

The method takes into account that the wear process at the macro level is an evolutionary, non-stationary random process. The determination of the parameters of a random process is based on the correspondence between the parameters of the mathematical model and the physical characteristics of the wear process. The method for determining the model parameters is invariant to methods for obtaining the physical characteristics of the process.

To describe the wear of elements of friction pairs, arrays of probability vectors of wear values of discrete points of the surface, called "triboelements", are used. Triboelements are modeled by non-stationary random processes of the Markov type. The change in the size of the bodies in the direction perpendicular to the friction surface is estimated using the mathematical expectation of the probability of the presence of triboelements in a certain state. The shape of the worn surface is determined using the cubic spline approximation of the mathematical expectations of wear at the points of location of the triboelements, which ensures a minimum of potential energy of the wear surface.

In accordance with the method, wear is described by a random Markov process with discrete time and states [13]. At time $t=1$ the probabilities of finding triboelements are defined as the product of the vector of initial states and the transition probability matrix (TPM) $\left[\mathbf{W}_{\mathrm{ij}}\right]$ : 


$$
\left[\boldsymbol{\pi}_{j}(t=1)\right]=\left[\boldsymbol{\pi}_{j}(t=0)\right]\left[\mathbf{W}_{\mathrm{ij}}\right], \quad i, j=1,2, \ldots, K_{C},
$$

where $\left[\pi_{j}(t=0)\right]$ is the vector of initial states; $\left[\pi_{j}(t=1)\right]$ is the vector of unconditional probabilities of finding triboelements in $j$ states at time $t=1 ;\left[\mathbf{W}_{\mathrm{ij}}\right]$ is the transition probability matrix.

The components of the imitial state vector $\left[\pi_{j}(t=0)\right]$ are determined from the assumption that at the initial moment of time the triboelement was in the first state:

$$
\left[\pi_{j}(t=0)\right]=[1,0,0, \ldots 0]
$$

If more detailed information is known about the probabilities of finding the triboelements at the initial moment of time (for example, dispersion of the initial parameters of the elements of the tribosystem), the vector of initial states may have a different form.

Probabilities of the state of triboelements at time $t>1$ defined as a product $\left[\pi_{f}(t-1)\right]$ vector of unconditional probabilities at the moment $t-1$ on the transition probability matrix, defining behavior of a triboelement at a time $t$.

$$
[\pi,(t)]=\left[\pi_{j}(t-1)\right]\left[\mathrm{w}_{\mathrm{ij}}\right], \quad i, j=1,2, \ldots, K_{\mathrm{C}}
$$

To describe the behavior of triboelements, a matrix of transition probabilities with single jumps up and the presence of an absorbing state is used:

$$
\left[\mathrm{W}_{\mathrm{ij}}\right]=\left[\begin{array}{cccccc}
w_{11}(t) & w_{12}(t) & 0 & 0 & \ldots & 0 \\
0 & w_{22}(t) & w_{23}(t) & 0 & \ldots & 0 \\
\ldots & \ldots & \ldots & \ldots & \ldots & \ldots \\
0 & 0 & 0 & 0 & \ldots & 1
\end{array}\right]
$$

The components of the matrix $w_{i j}(t)$ are defined as follows:

$$
w_{i j}(t) \cong \lambda_{I}(t) \Delta t
$$

where $\lambda_{I}(t)=V_{I}(t) / h$; is the wear flow rate; $\Delta t$ is the time step; $h=\varepsilon /\left(K_{C}-1\right)$ is the value determined from the condition of ordinary wear flow; $V_{I}(t)$ is the wear rate at time.

It should be noted that the wear rate function is invariant with respect to the methods of its preparation. As a function, one can use both the approximation functions of empirical data and the dependences obtained by calculation methods. Through the function of the wear rate, the main characteristic of the wear flow, represented in the form of a Markov chain, is determined as the intensity of the wear flow $\lambda_{f}(t)$, which determines the transitions of a system from state to state. fracture.

The wear flow rate can be determined by the calculation method [9], based on the thermokinetic theory of

$$
\begin{aligned}
& \lambda_{I}(t)=\frac{1}{h \tau_{0}} \times \\
& \times \exp \left(-\frac{U_{0}-\left[\frac{\sigma_{N}(x, y, z, t) \cdot M \cdot L_{5} \cdot\left(f_{d}+\left(f_{1}-f_{d}\right) \cdot e^{\left(-\beta v_{2}\right)}\right)}{h_{w}}\right] \pm \Delta G}{R T(x, y, z, t)}\right)
\end{aligned}
$$


where $\sigma_{N}(x, y, z, t), T(x, y, z, t)$ is the contact pressure and temperature, respectively, at the point with coordinates $(x, y, z)$ at the time $t ; f_{d}$ is the dynamic coefficient of friction; $f_{z}$ is the static coefficient of friction; $v_{s, k}$ is the relative sliding speed at the point of contact; $\beta$ is the coefficient; $L_{s}$ is the sliding friction path; $M$ is the molar volume; $h_{w}$ is the wear layer thickness; $U_{0}$ is the activation energy of the leading mechanism of destruction; $\Delta G$ is the coefficient taking into account the influence of the external environment; $R$ is gas constant.

Dependence of wear flow rate $\lambda_{I}(t)$ can be used to simulate tribosystems with a wide range of input parameters.

The value of wear is determined through the mathematical average $\bar{m}_{l}$ :

$$
z_{t}=\left(\bar{m}_{t}-1\right) h
$$

where $\bar{m}_{t}=\sum_{i=1}^{K_{C}} i \pi_{\mathrm{i}}(t), i=1,2, \ldots, K_{C} ; \boldsymbol{\pi}_{\mathbf{i}}(t)$ is the vector of unconditional probabilities of triboelement states,

Topological equations describing the relationships in the composition of the simulated system are represented by a cubic spline approximation of the mathematical expectations of wear. This provides a minimum of potential energy of the wear surface:

$$
\begin{aligned}
& Z_{k, \nu}(l)=\frac{1}{6 d_{k, \nu}}\left[M_{k, \mu}\left(l_{k, \nu+1}-l\right)^{3}+M_{k, \nu+1}\left(l-l_{k, \lambda}\right)^{3}\right]+ \\
& +\frac{1}{d_{k, \nu}}\left[\left(Z_{k, \mu}-\frac{M_{k, \mu} d_{k, \nu}^{2}}{6}\right)\left(l_{k, \mu+1}-l\right)+\left(Z_{k, \mu+1}-\frac{M_{k, \nu+1} d_{k, \nu}^{2}}{6}\right)\left(l-I_{k, \nu}\right)\right],
\end{aligned}
$$

where $d_{k, u}=l_{k, u+1}-l_{k \mu} ; k=1,2, \ldots, K, u=1,2, \ldots, U ; K, U$ is the number of triboelements with wear in the radial and axial directions.

$M_{k, \mu}$ are determined from systems of linear equations for each $k$ :

$$
\begin{aligned}
& d_{k \mu} M_{k, u}+2\left(d_{k, u}+d_{k, u+1}\right) M_{k, u+1}+d_{k \mu+1} M_{k, u+2}= \\
& =6\left(\frac{Z_{k, u+2}-Z_{k, u+1}}{d_{k, u+1}}-\frac{Z_{k, u+1}-Z_{k, \mu}}{d_{k \mu}}\right)
\end{aligned}
$$

Cubic spline function of the dependence of wear values is:

$$
\begin{aligned}
& Z_{r-1}\left(l_{1}, \varphi\right)=\frac{1}{6 d_{r}}\left[M_{r}\left(\varphi_{r+1}-\varphi\right)^{3}+M_{r+1}\left(\varphi-\varphi_{r}\right)^{3}\right]+ \\
& +\frac{1}{d_{r}}\left[\left(Z_{r}-\frac{M_{r} d_{r}^{2}}{6}\right)\left(\varphi_{r+1}-\varphi\right)+\left(Z_{r+1}-\frac{M_{r+1} d_{r}^{2}}{6}\right)\left(\varphi-\varphi_{r}\right)\right],
\end{aligned}
$$

where $d_{r}=\varphi_{r+1}-\varphi_{r} ; \quad r=1,2, \ldots, K_{I}$.

$M_{r}$ is determined from a system of linear equations:

$$
d_{r}, M_{r}+2\left(d_{r}+d_{r+1}\right) M_{r+1}+d_{r+1} M_{r+2}=6\left(\frac{Z_{r+2}-Z_{r+1}}{d_{r+1}}-\frac{Z_{r+1}-Z_{r}}{d_{r}}\right) .
$$

\section{Generalized interaction algorithm for the wear calculation module with CAD / CAM / CAE systems}

The effectiveness of the calculation method will depend on how much the basic requirements for the mathematical support of CAD / CAM / CAE systems and the architectural features of the software package for its implementation are taken into account. 
To consider the influence of wear processes on the behavior of the technical system in information technology, it is necessary to ensure the interaction of the calculation modules of the software complex, taking into account changes in the input parameters at each step of the itcrative process.

For example, the initial data for determining the parameters of the wear model are the results of the analysis of the stress-strain state of the elements of the friction pair. On the other hand, the stress-strain state depends on geometric parameters that change due to wear of the elements. In addition, the dynamic processes occurring in the system influence the stress-strain state. The dynamic behavior of the system determines, among other things, the wear of elements of friction pairs.

In connection with the above, a generalized algorithm for the interaction of the module for calculating wear by the triboelement method with the $\mathrm{CAD} / \mathrm{CAM} / \mathrm{CAE}$ complex can be represented as follows.

1. Construction of a geometric model of a technical system using a CAD / CAM / CAE complex preprocessor, including tribopairs.

2. Construction by means of $\mathrm{CAD} / \mathrm{CAM} / \mathrm{CAE}$-complex of the calculated finite-element model of the system and tribopairs.

3. Saving the set of coordinates of the nodes of the finite elements of the tribological conjugation located on the wear surface.

4. Determination of the stress-strain state of the elements of the technical system (including tribological conjugation elements) using the solver CAD / CAM / CAE-complex, taking into account a given set of input parameters

5. Determination of the parameters of the wear model using the obtained results of the solution of p. 4 in the wear calculation module. The parameters are the values of the components of the transition probability matrix for each node of the finite element that has come into contact.

6. In the module for calculating wear, the mathematical expectation of the amount of wear is determined for each node of the final element located on the wear surface and which has come into contact. Saving the obtained vectors of unconditional wear probabilities for finite element nodes.

7. Determination of the amount of wear and the set of new coordinates of the nodes of the finite elements located on the wear surface.

8. By means of the CAD / CAM / CAE complex, the set of coordinates of the nodes of finite elements located on the wear surface and having wear is adjusted (taking into account the results obtained (p. 7)).

9. The cyclic repetition of p.p. 4-8 until the specified boundary operating time of the technical system or the specified parameters of the state of the system.

\section{Approbation of the proposed solutions}

The proposed solutions for improving the mathematical support of information technology, the interaction algorithms of the wear calculation module with the elements of a $\mathrm{CAD} / \mathrm{CAM} / \mathrm{CAE}$ complex have been tested.

Using this method, new results were obtained by calculation, which received experimental confirmation. The method of tribo elements was verified by comparison with empirical and calculated data available in the literature. For various types and conditions of functioning of tribosystems, sufficient accuracy and efficiency of the method was obtained in solving tribotechnical problems [13 - 16].

To test the mathematical models of the method, software was developed to calculate the wear of various types of friction units (Fig. 1, 2). The software was implemented both in the form of autonomous modules (Fig. 1), and in the form of computational modules integrated into the CAD / CAM / CAE complex (Fig. 2).

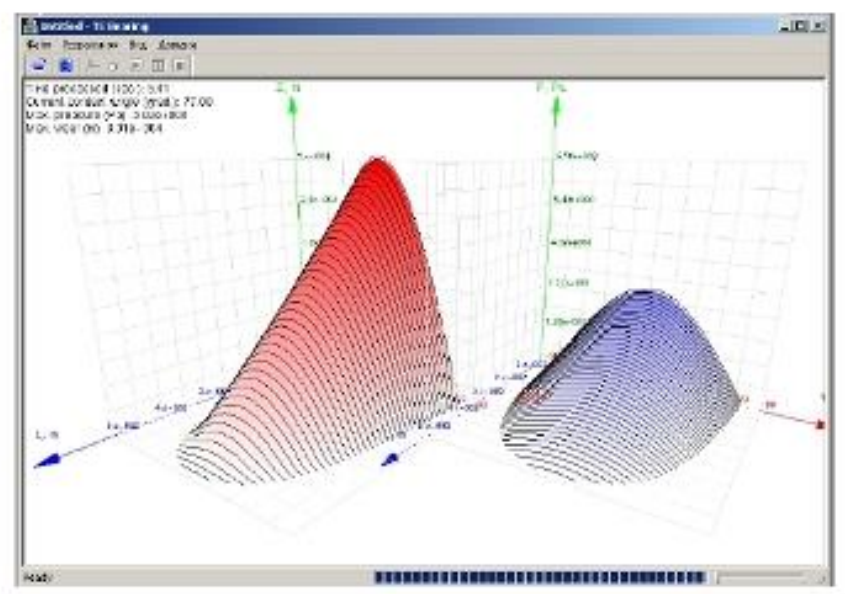

Fig. 1. The results of the calculations of the autonomous module 
When implementing integrated calculation modules, a generalized algorithm for the interaction of the wear calculation module with $\mathrm{CAD} / \mathrm{CAM} / \mathrm{CAE}$ systems was implemented and tested.

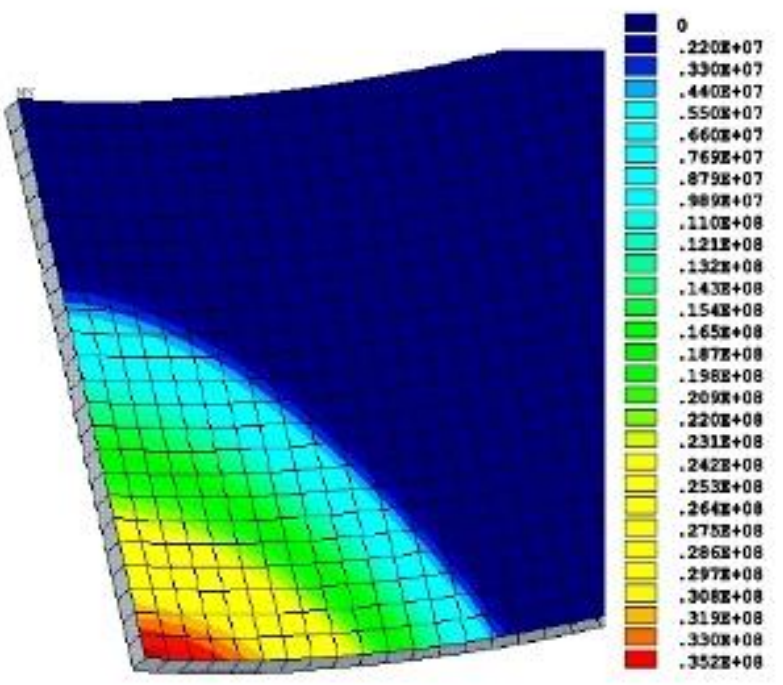

Fig. 2. The results of the calculations of the integrated module

The testing of the mathematical support of information technology was carried out both for normal operating conditions of technical systems [13 - 15], and for systems operating in extreme conditions [16-17]. Mathematical models have shown sufficient accuracy in assessing the wear of rifled small arms trunks [16].

\section{Conclusion}

Based on the analysis, it is proposed to use the triboelement method as the basic method of mathematical support of information technology for $\mathrm{CAD} / \mathrm{CAM} / \mathrm{CAE}$-systems of the tribological sector. This method most fully takes into account the basic requirements for the $\mathrm{CAD} / \mathrm{CAM} / \mathrm{CAE}$ systems of mathematical software and can be implemented in software systems. The proposed solutions to improve the mathematical support of information technology, the interaction algorithms of the wear calculation module with the elements of the $\mathrm{CAD} /$ CAM / CAE complex are quite approved. The proposed generalized algorithm for the interaction of the wear calculation module with $\mathrm{CAD} / \mathrm{CAM} / \mathrm{CAE}$ - systems has been implemented and tested by implementing the software of integrated calculation modules.

\section{References}

1. Hegadekatte V., Huber N., Kraft O.: Finite element based simulation of dry sliding wear. Modelling Simul. Mater. Sci. Eng. N.13. pp. 57-75. (2005). doi: 10.1088/0965-0393/13/1/005

2. Hegadekatte, V., Huber, N. \& Kraft, O.: Modeling and simulation of wear in a pin on disc tribometer. Tribol Lett 24, 51 (2006). doi: 10.1007/s11249-006-9144-2

3. Kim N. H., Won D., Burris D., Holtkamp B.: Finite element analysis and experiments of metal/metal wear in oscillatory contacts. Wear. N. 258. pp. 1787-1793. (2005). doi: 10.1016/j.wear.2004.12.014

4. Thompson, J.M. Thompson M.K.: A Proposal for the Calculation of Wear. Proceedings of the 2006 International ANSYS Users Conference \& Exhibition, Pittsburgh, PA. (2006).

5. Azeem Ashraf, M., Sobhi-Najafabadi, B., Göl, Ö. et al.: Numerical simulation of sliding wear for a polymer-polymer sliding contact in an automotive application. Int J Adv Manuf Technol 41, 1118-1129 (2009). doi: $10.1007 / \mathrm{s} 00170-008-1560-z$

6. ANSYS Resource Library. https://www.ansys.com/resource-library.

7. ANSYS Basic Analysis Procedures Guide. ANSYS Release 11. ANSYS Inc., (2008).

8. LS-DYNA R10.0 Theory Manual, Livermore Software Technology Corporation, (2017).

9. Hallquist, J.O.: LS-DYNA Keyword User's Manual, Livermore Software Technology Corporation, (2003).

10. MSC.Software Corporation. Marc/Mentat 2008 What's New, (2008).

11. MSC.Software Corporation. User Documentation: Marc $2008 \mathrm{r} 1$,Vol. A: Theory and User Information.

12. MSC Software Corporation. User Documentation: Marc 2008 r1, Vol. E. Demonstration Problems.

13. Sorokatyi R. V.: Simulation of tribosystem behavior by the method of triboelements. J. Friction and Wear, Vol. 23, pp. 12-18. (2002). 
14. Sorokatyi R.V., Pisarenko V.G., Dykha M.A.: Analysis of Wear Surface Geometry Formation in Plain Bearings with Misaligned Shaft and Bush Axes, J. Friction and Wear, Vol. 34, pp. 274-280. (2013). doi: $10.3103 /$ S1068366613040119

15. Dykha A., Sorokatyi R., Makovkin O., Babak O.: Calculation-experimental modeling of wear of cylindrical sliding bearings. Eastern-European Journal of Enterprise Technologies. Vol. 5, nr 1, pp.51-59. (2017). doi: 10.15587/1729-4061.2017.109638

16. Sorokatyi R. V., Dykha A. V.: Analysis of Processes of Tribodamages under the Conditions of HighSpeed Friction. J. Friction and Wear, Vol. 36, pp. 422-428. (2015). doi: 10.3103/S106836661505013X

17. Sorokatyi, R., Chernets, M., Dykha, A., Mikosyanchyk, O. Phenomenological Model of Accumulation of Fatigue Tribological Damage in the Surface Layer of Materials (2019) Mechanisms and Machine Science, 73, pp. 3761-3769. https://ink.springer.com/chapter/10.1007\%2F978-3-030-20131-9 371 
Сорокатый Р., Дыха А., Пасечник А., Скрыпник Т. Компыотерно-информацнонные технологини модетирования трибологнческих систем

Предложено для совершенствования элементов информацнонной технологии $\mathrm{CAD} / \mathrm{CAM} / \mathrm{CAE}$ систем триботехнического назначения использовать метод трибоэлементов. Математическое обеспечение информационной технологии и обобщенный алгоритм взаимодействия модуля расчета износа с элементами CAD/CAM/CAE - снстем прошли достаточную апробацию путем реализации программного обеспечения и верифнкацни полученньх результатов расчета.

Ключевые слова: информацнонная технология, математическое обеспеченне, $\mathrm{CAD} / \mathrm{CAM} / \mathrm{CAE}$, метод трибоэлементов, автоматизация проектирования 